\title{
Effect modification, interaction and mediation: an overview of theoretical insights for clinical investigators [Corrigendum]
}

\author{
Corraini P, Olsen M, Pedersen L, Dekkers OM, Vandenbroucke \\ JP, Clin Epidemiol. 2017;9:331-338.
}

On pages 333-334, the interaction contrast appeared incorrectly as 1.5 per 1,000 person-years, where it should read -1.5 per 1,000 person-years. This occurred from an inversion between the result of the rate reduction of heart disease due to aspirin among those receiving warfarin $(10.3-8.7=1.6)$ and the result of the rate reduction due to aspirin among those not receiving warfarin $(13.3-10.2=3.1)$.

The interpretation of the interaction contrast should then read in page 334 as: "As the interaction contrast was below zero, it could be concluded that the effect of combining warfarin and aspirin in reducing ischemic heart disease was lower than that expected by the sum of the effects of either agent on its own."

This corrigendum had no consequences for the educational message of our paper.

\section{Publish your work in this journal}

Clinical Epidemiology is an international, peer-reviewed, open access, online journal focusing on disease and drug epidemiology, identification of risk factors and screening procedures to develop optimal preventative initiatives and programs. Specific topics include: diagnosis, prognosis, treatment, screening, prevention, risk factor modification, systematic reviews, risk and safety of medical interventions, epidemiology and biostatistical methods, and evaluation of guidelines, translational medicine, health policies and economic evaluations. The manuscript management system is completely online and includes a very quick and fair peer-review system, which is all easy to use. 